\title{
Sexual function after sacrospinous fixation for vaginal vault prolapse: bad or mad?
}

\author{
Marc Baumann · Claudia Salvisberg • \\ Michel Mueller · Annette Kuhn
}

Received: 14 March 2008/ Accepted: 13 July 2008/Published online: 24 September 2008

(C) Springer Science+Business Media, LLC 2008

\begin{abstract}
Background The main indication for sacrospinous ligament suspension is to correct either total procidentia, a posthysterectomy vaginal vault prolapse with an associated weak cardinal uterosacral ligament complex, or a posthysterectomy enterocele. This study aimed to evaluate sexual function and anatomic outcome for patients after sacrospinous ligament suspension.

Methods For this study, 52 patients who had undergone sacrospinous ligament fixation during the preceding 5 years were asked to complete the Female Sexual Function Index (FSFI) questionnaire. The patients were vaginally examined using the ICS POP score, and the results were compared with their preoperative status. For statistical analysis, GraphPad for Windows, version 4.0, was used.

Results The 52 patients were examined during a followup period of 38 months. No major intraoperative complications were noted. Recurrence of symptomatic apical descent was noted in $6 \%$ of the patients and de novo prolapse in $13.5 \%$. Only one patient was symptomatic. Three patients experienced de novo dyspareunia, which resolved in two cases after stitch removal. Sexual function was good, rating higher than three points for each of the domains including satisfaction, lubrication, desire, orgasm, and pain.

Conclusion Sacrospinous ligament fixation still is a valuable option for the treatment of vaginal vault prolapse.
\end{abstract}

M. Baumann · C. Salvisberg · M. Mueller · A. Kuhn $(\bowtie)$ Department of Obstetrics and Gynaecology, Inselspital, Bern University Hospital and University of Bern, Effingerstrasse 102, CH-3010 Bern, Switzerland

e-mail: annette.kuhn@insel.ch
Sexual function is satisfactory, with few cases of de novo dyspareunia.

Keywords Gynecology - Obstetrics - Sexual function · Vaginal vault prolapse

The vaginal approach to prolapse surgery carries significant low postoperative morbidity. Sacrospinous ligament suspension was described originally in 1951 by Amreich [1] and then in 1968 by Richter [2].

The main indication for sacrospinous ligament suspension is to correct either total procidentia, a posthysterectomy vaginal vault prolapse with an associated weak cardinal uterosacral ligament complex, or posthysterectomy enterocele $[3,4]$.

The operation also has been suggested as a prophylactic step at the time of vaginal hysterectomy against subsequent vaginal vault prolapse $[5,6]$ or for patients with symptomatic prolapse who wish to retain their uterus $[7,8]$.

Sacrospinous ligament suspension usually is performed via the posterior approach, starting with a longitudinal incision in the posterior vaginal wall. The sacrospinous ligament is dissected, after which sutures are placed $2 \mathrm{~cm}$ medial to the spine, thus avoiding injury to the pudendal complex. Sacrospinous fixation can be performed unilaterally or bilaterally.

The operation is effective in $77 \%$ to $82 \%$ of cases $[4,9$, 10] but does distort the vaginal axis, predisposing to future anterior compartment defects with an incidence of $20 \%$ to $92 \%$ [11, 12]. Intra- and postoperative complications include hemorrhage with a $2 \%$ transfusion risk, injury to the pudendal nerve, and injury to neighboring organs [13-15].

Because of the distorted vaginal axis, dyspareunia is a postoperative complication with an incidence ranging from 
$0 \%$ to $16 \%[16,17]$. Additional potential complications include voiding dysfunction, postoperative urinary incontinence, and evisceration [18]. However, data on sexual function using validated questionnaires are scarce, and most of the studies have asked the patients only about the presence or absence of dyspareunia. Generally, sacrospinous fixation is an operation considered for the sexually less active patient.

The Female Sexual Function Index (FSFI) is a brief, self-report measure of female function that evaluates six different domains of sexual function: desire, subjective arousal, lubrication, orgasm, satisfaction, and pain. First described by Rosen et al. [19] in 2000, the FSFI is widely used to assess sexual function.

This study aimed to evaluate sexual function and anatomic outcome for patients after sacrospinous ligament suspension.

\section{Methods}

All patients who had undergone sacrospinous ligament fixation for symptomatic vaginal vault descent during the preceding 5 years were asked to attend the outpatient department. Patients were identified using the hospital's operating registry and asked to complete the FSFI questionnaire. The patient's history was taken, and pelvic organ prolapse was determined according to the ICS standardization (ICS POP-Q).

All operations were performed by three senior surgeons in a standardized manner. With the patient in lithotomy position, the posterior vaginal wall was incised longitudinally from the introitus to the vault, exposing the rectovaginal space. The epithelium was dissected laterally to both sides. The right ischial spine was palpated and exposed by creation of a space through the right rectal pillar using sharp and blunt dissection. The sacrospinal ligament was palpated and exposed using a Breisky spekula. A double permanent suture (Ethibond, Johnson \& Johnson, Ethicon, CH-Spreitenbach) was placed through the ligament under direct vision $2 \mathrm{~cm}$ medial to the ischial spine. The sutures were loaded onto a loose needle and passed through the vaginal epithelium at the vaginal vault on each side and held for later tying.

An enterocele, if present at all, was dissected out and obliterated with one or two purse-string sutures. The rectovaginal septum was reconstructed with polyglycolic sutures using Vicryl 2-0. If necessary, a concomitant cystocele or rectocele was corrected accordingly with polyglycolic sutures. A suburethral sling was inserted if indicated.

The vaginal epithelium was closed, and the sacrospinous sutures finally were tied in a manner resembling a pulley bringing the vaginal vault up to the ligament. A vaginal pack and Foley catheter were left in situ.
Follow-up assessment was performed by an independent observer (C.S.) who had not been involved in the surgical procedure and who was blinded to the patient notes.

Any postoperative complications and interventions were noted. Statistical analysis was performed using GraphPad version 4.0 for Windows and Prism version 5.0 for Windows (GraphPad Software, La Jolla, CA, USA).

\section{Results}

Of the 83 patients who had undergone a sacrospinous fixation, 13 were deceased, 9 had moved to distant areas and were not willing to travel, 5 refused to participate in the study, and 4 returned no response. Of the remaining 52 patients, 47 were sexually active and completed the FSFI questionnaire.

The median follow-up period after the operations was 36 months (range, 6-42 months). Table 1 presents the patients' demographic data. Eight patients had a history of instrumental delivery. Eight patients had undergone a cesarean section, and 34 patients had experienced a spontaneous delivery. Two patients were nullipareous. A total of 49 patients were postmenopausal, 19 of whom were receiving systemic hormone replacement therapy (HRT). Two patients were perimenopausal, and one was premenopausal.

Before their operation, 35 patients had a stage 2 vault descent and 17 had a stage 3 vault prolapse. A cystocele was found in 17 patients and a rectocele in 9 patients. Eight patients had shown preoperative urodynamic stress incontinence, and five patients had masked incontinence.

Table 2 shows the surgical procedures performed in addition to sacrospinous fixation. Two patients required intraoperative bladder suturing due to iatrogenic bladder lesion. There were no rectal injuries and no bleeding necessitating transfusion.

The patients had a median operating time of $90 \mathrm{~min}$ (range, 60-230 min), a median blood loss of $100 \mathrm{ml}$ (range, 50-600 ml), and a median hospital stay of 6 days (range, 3-15 days). Pelvic floor testing resulted in a median of 2 (range, 0-4). Prolapse staging at the follow-up assessment is shown in Fig. 1.

Symptomatic apical descent was noted in three cases, symptomatic rectoceles in five cases, and symptomatic

Table 1 Demographic data

\begin{tabular}{lll}
\hline & Median & Range \\
\hline Age & 67 & $50-87$ \\
Body mass index (BMI) & 25 & $21-33.2$ \\
$\begin{array}{l}\text { Weight of heaviest } \\
\text { baby (g) }\end{array}$ & 3,500 & $2,710-4,800$ \\
\hline
\end{tabular}


Table 2 Additional procedures

\begin{tabular}{lcc}
\hline Procedure & No. of patients & $\%$ \\
\hline Anterior repair & 17 & 33 \\
Posterior repair & 9 & 18 \\
Enterocele resection & 5 & 10 \\
Suburethral sling & 13 & 25 \\
\hline
\end{tabular}

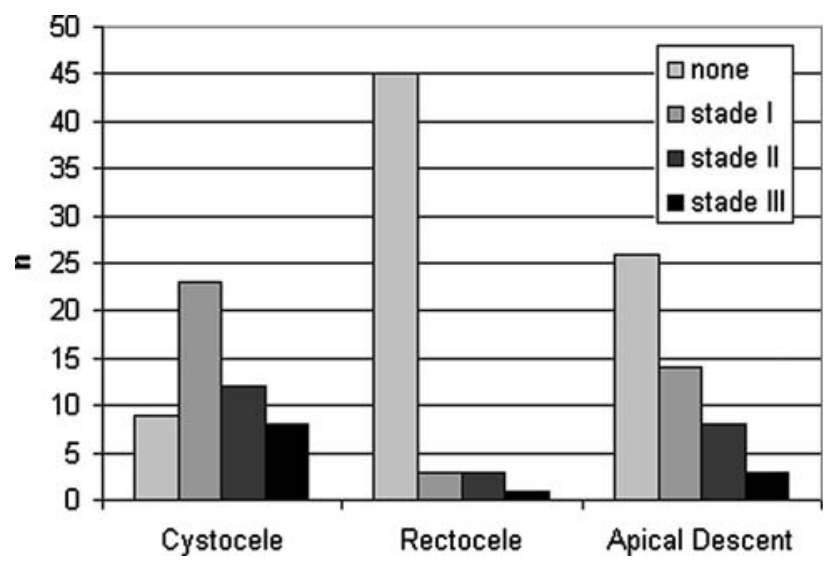

Fig. 1 Postoperative prolapse staging

cystoceles in three cases. Further surgery was required for six patients and conservative therapy for five patients.

Seven patients (13.5\%) experienced a de novo prolapse, which proved to be stage 2 cystocele in four cases, stage 2 rectocele in three cases, and symptomatic in only one case. De novo stress urinary incontinence was experienced by two patients. All 13 patients managed with a tension-free vaginal tape had a negative cough test postoperatively and were subjectively continent. At this writing, two patients have experienced recurrent urinary tract infections $(>2 /$ year) and currently are under further investigation. Figure 2 presents the results of the FSFI questionnaire (bars $=$ means with $95 \%$ confidence intervals).

In terms of pain, three patients experienced de novo dyspareunia after sacrospinous fixation. Two of these patients had granulatous tissue around the Ethibond sutures. This tissue was surgically removed, and estrogen cream was applied. The lesion healed, and at follow-up assessment, the patients had resumed intercourse without further pain. These women experienced no recurrence of vault prolapse.

\section{Discussion}

The quality of life for older adults is determined primarily by personal relationships, health status, and sexual activity [20]. This study shows that 3 years after intervention, sacrospinous fixation is an efficacious operation with few

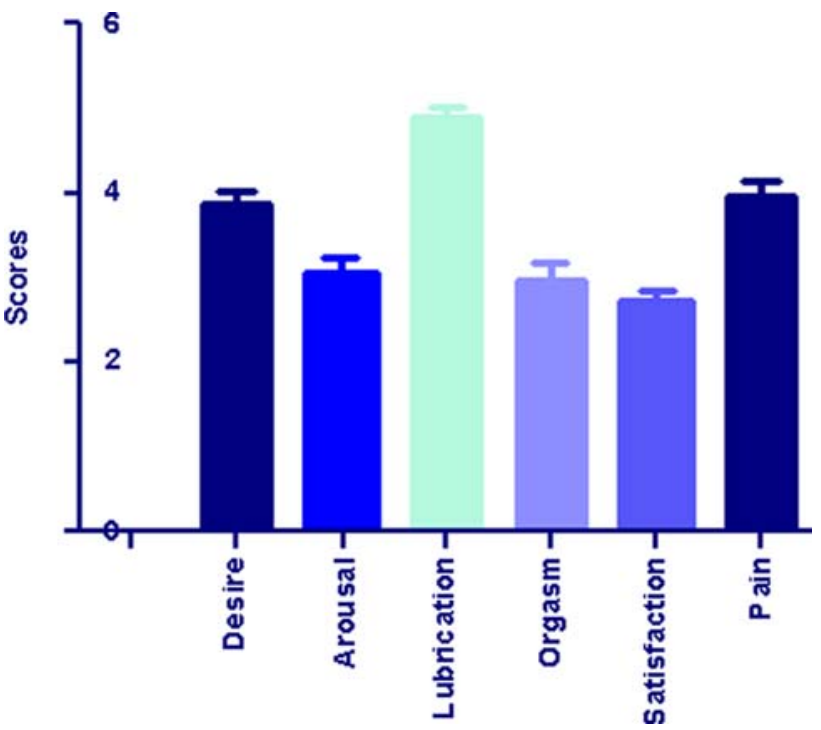

Fig. 2 Results of the Female Sexual Function Index (FSFI)

intra- and postoperative complications. Despite alteration of the anatomic vaginal axis in unilateral sacrospinous fixation, the patients are mainly satisfied with their sexual life, as demonstrated by the FSFI results. The score of 4.2 obviously shows that painful intercourse is not an important postoperative issue. However, $6 \%$ of our patients experienced de novo dyspareunia, so it is a noteworthy long-term complication.

Our findings agree with those of Richter and Albrich [16], who suggested that sacrospinous fixation does not predispose to dyspareunia unless vaginal narrowing occurs due to repair of associated defects and reported a $10 \%$ apareunia rate for 36 patients. Fortunately, we found no case of apareunia or any substantial narrowing in our series.

Sufficient vaginal capacity and lubrication is known to be influenced positively by the local estrogen treatment [21] we used postoperatively. Thus, local estradiol valerate also may be responsible for the improvement in sexual function and the prevention of vaginal narrowing.

One-third of our patients had an anterior repair performed in addition to sacrospinous vault suspension. The "G-spot" on the anterior vaginal wall is a supersensitive area for some women. The exact site differs among women [22]. Because sensitivity of the anterior vaginal wall may be altered by the creation of scars in this area, sexual function also may be altered. However, only a few data on that issue are available.

A weakness of the study is that only a midterm followup assessment was performed. Sexual function was not evaluated before the intervention, so we cannot determine improvement or deterioration postoperatively.

The patients were rather shy about answering very personal questions relating to their sexual life. One reason may be that the study patients were rather elderly (median 
age, 67 years) and consequently were not used to communicating about their sex life. In a recent study by Smith et al. [23], only $4 \%$ of the interviewed women reportedly initiated a discussion about sexual function with their physician in the preceding year, compared with a remarkably higher percentage of men who did so $(36 \%)$.

Our patients were rather more active sexually (90\%) than those in comparable other studies, in which only $48 \%$ of elderly women 75 to 84 years of age were sexually active $[24,25]$. This may be due to our rather "positive" selection, in which perhaps only sexually active women willing to participate in the study on sexual function were included.

None of our patients experienced de novo urinary incontinence, possibly because of preoperative urodynamics and simultaneous sling implantation in the case of masked incontinence. However, the question of whether slings should be used simultaneously in prolapse operations is not clearly answered because a recent American study calculated that 27 slings must be implanted to prevent one patient from de novo urinary incontinence [25]. We have not specifically enquired about bowel function in our follow-up assessments, which is a weakness of this study.

The complication rate in our series was low compared with the rate in a recent study [26]. However, in that study, bilateral sacrospinous fixation was performed, which explains the complication rate of $17 \%$. The only major postoperative complication in that study was a pararectal hematoma, which necessitated repeat surgery, and this complication was experienced by a woman receiving highdose anticoagulation. The patient satisfaction rate after bilateral sacrospinous fixation was high (93\%), which may be due to the bilateral vault suspension used rather than the unilateral suspension used in our study. Similar to our study, sexual function improved for $90 \%$ of the women after sacrospinous fixation.

The primary question addressed in our study was about sexual function, and this question was answered: Most of the sexually active patients were content with their libido, sexual arousal, lubrication, and sexual function overall after sacrospinous fixation. However, the possibility of postoperative dyspareunia should be discussed with the patient before the intervention.

Future studies need to address sexual function when vaginal surgery is investigated.

Few surgeons suggest sacrospinous fixation to sexually active patients, and obviously, the abdominal approach in terms of sacrocolpopexy is the better option for improvement of pelvic floor symptoms, including sexual function [27] and physiological positioning of the vaginal axis.

Sexual function after sacrospinous fixation is neither bad nor mad but satisfactory for most of patients. Few intra- and postoperative complications suggest that this method is a valuable option for elderly patients.

\section{References}

1. Amreich Aetiologie und Operation des Scheidenstumpfprolpases (1951) Wien Klin Wochenschr 63:74-77

2. Richter K (1968) Die chirurgische Anatomie der Vaginaefixation sacrospinalis: Ein Beitrag zur operativen Behandlung des Scheidenblindsackprolapses. Geburth Frauenheilk 28:321-327

3. Carey MP, Slack MC (1994) Transvaginal sacrospinous colpopexy for vault and marked uterovaginal prolapse. Br J Obstet Gynecol 101:536-540

4. Morley GW, DeLancey JO (1988) Sacrospinous ligament fixation for eversion of the vagina. Am J Obstet Gynecol 158:872-881

5. Cruikshank SH, Cox DW (1990) Sacrospinous ligament fixation at the time of transvaginal hysterectomy. Am J Obstet Gynecol 162:1611-1619

6. Cruikshank SH (1991) Sacrospinous fixation: should this be performed at the time of vaginal hysterectomy? Am J Obstet Gynecol 164:1072-1076

7. Hefni M, El-Thouky T, Bhaumik J, Katsimanis E (2003) Sacrospinous cervicocolpopexy with uterine conservation for uterovaginal prolapse in elderly women: an evolving concept. Am J Obstet Gynecol 188:645-650

8. Kovac RC, Cruikshank SH (1993) Successful pregnancies and vaginal deliveries after sacrospinous uterosacral fixation in five of nineteen patients. Am J Obstet Gynecol 168:1778-1790

9. Kettel ML, Herbertson RM (1989) An anatomic evaluation of the sacrospinous ligament colpopexy. Surg Gynecol Obstet 168:318-322

10. Peters WA, Christenson ML (1995) Fixation of the vaginal apex of the coccygeal fascia during repair of vaginal vault eversion with enterocele. Am J Obstet Gynecol 172:1894-1902

11. Paraiso MF, Ballard LA, Wallace MD (1996) Pelvic support defects and visceral and sexual function in women treated with sacrospinous ligament suspension and pelvic reconstruction. Am J Obstet Gynecol 175:1423-1431

12. Holley RJ, Varner RE, Gleason BP (1995) Recurrent pelvic support defects after sacrospinous ligament fixation for vaginal vault prolapse. J Am Coll Surg 180:444-448

13. Suckling J, Lethaby A, Kennedy R (2006) Local oestrogen for vaginal atrophy in postmenopausal women (review). Cochrane Database Syst Rev 18(4):CD001500

14. Sze EH, Karram MM (1997) Transvaginal repair of vault prolapse: a review. Obstet Gynecol 89:466-475

15. Barksdale PA, Gasser RF, Gauthier CM, Elkins TE, Wall LL (1997) Intraligamentous nerves as a potential source of pain after sacrospinous ligament fixation of the vaginal apex. Int J Pelvic floor Dysfunct 8:121-125

16. Richter K, Albrich W (1981) Long-term results following fixation of the vagina on the sacrospinous ligament by the vaginal route. Am J Obstet Gynecol 141:811-816

17. Holley RL, Varner RE, Gleason BP, Apffel LA, Scott S (1996) Sexual function after sacrospinous ligament fixation for vaginal vault prolapse. J Reprod Med 41:355-358

18. Estrade JP, Agostini A, Roger V, Dallay D, Blanc B, Cravello L (2004) Sacrospinous colpopexy complications. Gynecol Obstet Fertil 32:850-854

19. Farrell SA, Scotti TA, Ostergard D (1991) Massive evisceration: a complication following sacrospinous vaginal vault fixation. Obstet Gynecol 78:560-562

20. Rosen R, Brown C, Heiman J, Leiblum S, Meston C, Shabsigh R, Ferguson D, D'Agostino R Jr (2000) The Female Sexual Function 
Index (FSFI): a multidimensional self-report instrument for the assessment of female sexual function. J Sex Marital Ther 26:191208

21. Robinson JG, Molzahn AE (2007) Sexuality and quality of life. J Gerontol Nurs 33:19-27

22. Hines TM (2001) The G-Spot: a modern gynaecologic myth. Am J Obstet Gynecol 185:359-362

23. Smith LJ, Mulhall JP, Deveci S, Monaghan N, Reid MC (2007) Sex after seventy: a pilot study of sexual function in older persons. J Sex Med 4:1247-1253

24. Bancroft JHJ (2007) Sex and aging. New Engl J Med 357:820822

25. Scherlitz L, Dwyer P, Rosamilia A, Murray C, Thomas E, Taylor N, Hiscock R, Lim Y, Achtari C, De Souza A (2007) A prospective randomised controlled study comparing vaginal prolapse repair with and without tension free vaginal tape (TVT) in women with severe pelvic organ prolapse and occult stress incontinence. ICS annual meeting Rotterdam, Abstract 114

26. David-Montefiore E, Barranger E, Dubernard G, Nizard V, Antoine JM, Darai E (2007) Functional results and quality of life after bilateral sacrospinous ligament fixation for genital prolapse. Eur J Obstet Gynecol Reprod Biol 132:209-211

27. Handa VL, Zyczinski HM, Brubaker L, Nygaard I, Janz NK, Richter HE, Brown MB, Weber AM (2007) Pelvic disorders network: sexual function before and after sacrocolpopexy for pelvic organ prolapse. Am J Obstet Gynecol 197:629.e1-6 